\title{
IMPACTO DA GLOBALIZAÇÃO SOBRE O PRINCÍPIO DA EFICIÊNCIA
}

\author{
SANDRA PIRES BARBosa
}

1. Introdução - 1.1. Globalização como fenômeno - 1.2. Eficiência como princípio - 2. A globalização como fenômeno mundial - 2.1. Mudanças no Estado - 2.2. Delineamentos da globalização - 3. Influência da globalização na Reforma Administrativa - 3.1. Motivação da Reforma - 3.2. Contornos da Reforma - 4. O princípio da Eficiência no contexto da Reforma - 4.1. Significado de eficiência - 4.2. Conteúdo axiológico do princípio - 5. Conclusão - 5.1. Inserção constitucional - 5.2. Fortificação do princípio.

\section{Introdução}

\subsection{Globalização como fenômeno}

O presente trabalho tem por escopo demonstrar o fundamental papel da globalização na elevação da eficiência ao status de princípio constitucional.

A revolução das comunicações e da tecnologia, tornou o mundo, de certa forma, menor, aproximando os países e permitindo maior troca de informações e experiências de toda ordem. A redução das distâncias geográficas, em razão desses avanços tecnológicos e do primado da informação célere, foi sofrendo uma profunda intensificação, assumindo ares de marcha eminentemente econômica. A esse fenômeno de expansão de interesses das sociedade humanas tem-se denominado "globalização", cujo efeito de maior marca é a influência de um país ou grupo de países sobre outro.

Reflexo desse jogo de influência é o infindável número de reformas estatais que se vem operando por diversos países do mundo. Incontáveis Estados subdesenvolvidos e em desenvolvimento vêm, sob o pálio da globalização, desestatizando suas economias e promovendo profundas reformas tributárias e administrativas. 
O que se pretende nas páginas seguintes é mostrar que esse processo globalizador foi um dos motivos propulsores da reforma administrativa do Estado Brasileiro consagrada com a Emenda Constitucional no 19/98 - e que uma das idéias centrais dessa reforma é a da eficiência, erigida, por isso mesmo, à esfera constitucional.

\subsection{Eficiência como princípio}

Eficiência é a palavra de ordem na globalização e globalização, por sua vez, é fenômeno contemporâneo que vem influenciando indiscutivelmente as reformas estatais realizadas mundo afora.

Eficiência num mundo globalizado significa produção de bens e serviços de maior qualidade, com rapidez e em maior número, sendo irrelevante se esses bens ou serviços são provenientes de organizações privadas ou públicas.

"Com efeito, as pessoas querem ver seus interesses satisfeitos, pouco importando quem o faça: se será uma empresa ou entidade governamental, se nacional, multinacional ou estrangeira. Com isso, o 'nacionalismo' deixa de ser uma idéiaforça, uma aspiração capaz de compensar a pobreza, o sacrifício e o subdesenvolvimento, para voltar a ser apenas uma referência entre outras, não mais capaz de justificar a ineficiência".'

A eficiência é, assim, uma preocupação dos Estados modernos no contexto da globalização e, nessa linha, também é uma preocupação de suas estruturas administrativas. O que se quer é ver a Administração Pública dotada do dinamismo, celeridade e presteza, caracterizadores do universo privado.

Prega-se, pois, em larga escala a transição da Administração burocrática clássica, estatista, hierárquica e autoritária, para a Administração gerencial moderna, amplamente influenciada pelos modelos megaempresariais das grandes corporações.

A necessidade de eficiência, antes implícita na Administração Pública, tornou-se explícita com a reforma administrativa, cujo texto elevou-a à categoria de princípio administrativo-constitucional. Na qualidade de princípio constitucional, a eficiência possui o condão de direcionar o Direito Administrativo e suas normas.

\section{A globalização como fenômeno mundial}

Apresentaremos, de início, algumas considerações acerca do processo de globalização, a fim de compreendermos como e sob que circunstâncias ele surgiu. Essa análise preliminar do fenômeno é essencial à compreensão de sua influência no processo de reforma do Estado Brasileiro e em especial no princípio da eficiência.

1 Diogo de Figueiredo Moreira Neto, Globalização, Regionalização, Reforma do Estado e da Constituição, p. 2. 


\subsection{Mudanças no Estado}

A função e o poder do Estado, sua forma de relação com a sociedade e intervenção na mesma tem-se alterado diametralmente ao longo dos últimos séculos, em especial, e de forma mais dinâmica, nas últimas décadas.

Em meados do século XIX, começaram as reações contra o Estado Liberal, por suas consequências funestas no âmbito econômico e social. As grandes empresas transformaram-se em grandes monopólios, aniquilando as empresas de pequeno porte e fazendo surgir uma nova classe social - o proletariado - absolutamente miserável e doente, situação que tenderia a se agravar com o não-intervencionismo estatal pregado pelo liberalismo.

Com efeito, consolida-se, após a Segunda Guerra Mundial, o Estado Social, também chamado Estado do Bem-Estar, consubstanciando o deslocamento da preocupação Estatal da esfera da liberdade para a da igualdade. Para tanto, o Estado deveria intervir na ordem econômica e social, proporcionando o bem comum em substituição ao individualismo imperante no período do Estado Liberal.

Na contra-mão, pode-se, com a implantação desse modelo Estatal, verificar que houve um crescimento desmesurado do Estado, com sérios golpes ao princípio da separação de poderes, em virtude do fortalecimento do Poder Executivo, além de ineficiência na prestação de serviços públicos, em razão da supradimensão das estruturas administrativas e aumento da burocracia.

"A falência do hiper-estado resultante dos seus dois modelos contemporâneos, o do bem-estar social e o socialista, dominantes durante quase todo século vinte, fez ressurgir a consciência de que certos problemas não podem ser resolvidos por um Poder Central, por mais gigantesco e poderoso que seja, e até por isso mesmo. A advertência de DANIEL BELL, de que o Estado de tornou grande demais para os pequenos problemas e pequeno demais para os grandes problemas, tem redirecionado a atenção tanto para as potencialidades das unidades metanacionais, quanto das unidades infraestatais." 2

As consequiências negativas produzidas pelo Estado Social de Direito e pelo positivismo jurídico reclamavam novas transformações no papel do Estado e elas vieram mediante a introdução da idéia de Estado Democrático. Com isso o Estado, além de ser de Direito (protetor das liberdades individuais) e sem deixar de ser Estado Social (protetor do bem comum), passou a ser também Estado Democrático, almejando-se, com isso, a participação popular no processo político, nas decisões do governo e no controle da Administração Pública.

Ademais, o Estado Democrático de Direito, procura substituir a idéia de Estado legal, puramente formalista, por um Estado de Direito vinculado aos ideais de justiça, pretendendo-se, com isto, submeter o Estado ao Direito e não à lei em sentido apenas formal. Em suma, a noção de Estado Democrático concentra-se nesses dois pontos: participação do cidadão e justiça material.

2 Diogo de Figueiredo Moreira Neto, Globalização, Regionalização, Reforma do Estado e da Constituição, Revista de Direito Administrativo, p. 2. 
Já a idéia de Estado Subsidiário ${ }^{3}$ é mais recente e veio apenas acrescentar-se à de Estado Democrático. Aquele tipo de Estado apóia-se no princípio da subsidiariedade, segundo o qual: (1) o Estado deve abster-se de exercer atividades que o particular tem condições de exercer por sua própria iniciativa e com seus próprios recursos; (2) o Estado deve fomentar, coordenar, fiscalizar a iniciativa privada, de tal modo a permitir aos particulares, sempre que possível, o sucesso na condução de seus empreendimentos; (3) O Estado deve realizar parcerias com o setor privado, estimulando-lhe o desempenho.

Essa nova concepção dos papéis do Estado, difundida principalmente a partir dos anos 80 , tem promovido inúmeras reformas estatais mundo afora "com vistas a fazer reverter os males instaurados pelo Estado intervencionista: de um lado, visto do lado do cidadão, quer-se restaurar e prestigiar a liberdade individual e a livre concorrência; isso leva às idéias de privatização, fomento, parceria com o setor privado; visto do lado do Estado, quer-se alcançar a eficiência na prestação dos serviços públicos, o que leva à idéia de desburocratização." 4

Dando seguimento ao raciocínio, torna-se oportuno observar que as mudanças no perfil do Estado caminham paralelamente e de forma absolutamente integrada com o fenômeno da globalização, tudo resultado da estreita interação mundial decorrente da revolução das comunicações.

\subsection{Delineamentos da globalização}

A globalização não é um fenômeno novo na história, tendo assumido, ao longo do tempo, diferentes conotações. "A globalização já foi cultural, pelo poder do exemplo, como se deu no mundo helênico; foi política, pelo poder da espada, como no mundo romano; foi econômica, pelo poder das riquezas, como no mundo ibérico dos descobrimentos e religiosa, pelo poder da fé, como no mundo cristão." 5

O movimento globalizador dos nossos dias, entretanto, não só é mais amplo como mais profundo, posto que fruto da "Era do Conhecimento", onde indivíduos, grupos, sociedades e Estados interagem de forma cada vez mais próxima em virtude do apurado desenvolvimento científico e tecnológico.

A palavra "globalização", tal como a conhecemos, tem uma história breve e vertiginosa. "Embora tenha sido "inventada" em 1944 por dois autores - Reiser e Davies - que previam uma "síntese planetária de culturas" em um "humanismo

3 Maria Sylvia Zanella Di Pietro, Parcerias na Administração Pública: concessão, permissão, franquia, terceirização e outras formas. A autora distingue Estado subsidiário de Estado mínimo. "neste, o Estado só exercia as atividades essenciais, deixando tudo o mais para a iniciativa privada, dentro da idéia de liberdade individual que era inerente ao periodo do Estado Liberal; naquele, o Estado exerce as atividades essenciais, típicas do Poder Público, e também as atividades sociais e econômicas que o particular não consiga desempenhar a contento no regime da livre iniciativa e livre competição; além disso, com relação a estas últimas, o Estado deve incentivar a iniciativa privada, auxiliando-a pela atividade de fomento", p. 29.

4 Ibidem, p. 31.

5 Diogo de Figueiredo Moreira Neto, Op.cit., p. 1. 
global" (Scholte 1996), talvez suas raízes imediatas remontem aos anos 60, quando conheceu uma utilização marginal em certos círculos acadêmicos e teve uma ampla repercussão a metáfora de McLuhan sobre a configuração de uma "aldeia global" possibilitada pelas novas tecnologias de informação e comunicação ${ }^{6}$.

Mas a expressão propriamente dita, no sentido econômico que hoje prevalece, surge no início dos anos $80 \mathrm{em}$ reconhecidas escolas americanas de administração de empresas, difundindo-se através da imprensa e passando a ser rapidamente assimilada pelo discurso neoliberal.

Com efeito, a globalização, tal como a compreendemos hoje, tem cunho predominantemente econômico, podendo ser entendida como um processo crescente de abertura das economias nacionais ao fluxo das mercadorias e capitais alienígenas, com vistas à formação de um mercado global unificado.

Inúmeros autores preferem, entretanto, dar à globalização uma concepção mais ampla. Djason B. Della Cunha, por exemplo, em artigo intitulado "Globalização e ordem jurídica: o dilema da cidadania nos Estados Periféricos", entende ser a globalização "uma nova ordem paradigmática que opera a substituição do conceito de sociedade nacional pelo de sociedade global. Consiste também na mundialização de processos econômicos, como a circulação de capitais, a ampliação dos mercados ou a integração produtiva em escala mundial. Mas, comporta ainda fenômenos da esfera social, como a criação e expansão de instituições supranacionais, a universalização de padrões culturais e o equacionamento de questões concernentes à totalidade do planeta (meio ambiente, desarmamento nuclear, crescimento populacionais, direitos humanos, bioética etc)" 7 .

De uma forma ou de outra, o processo de globalização assenta-se na redução das distâncias geográficas, respaldando-se, como já frisado, nos avanços tecnológicos e no primado da informação célere.

Com a globalização, ocorrem inúmeras rupturas institucionais nas estruturas jurídicas e políticas legadas pelo Estado liberal, no século XIX, e pelo Estado social, no século XX. As rupturas mais importantes, segundo José Eduardo Faria ${ }^{8}$, são:

" 1 - mundialização da economia, mediante a internacionalização dos mercados de insumo, consumo e financeiro, rompendo com as fronteiras geográficas clássicas e limitando crescentemente a execução das políticas cambial, monetária e tributária dos Estados nacionais;

2 - desconcentração do aparelho estatal, mediante a descentralização de suas obrigações, a desformalização de suas responsabilidades, a privatização de empresas públicas e a "deslegalização" da legislação social;

3 - internacionalização do Estado, mediante o advento dos processos de integração formalizados pelos blocos regionais e pelos tratados de livre comércio e a

6 José María Gómez, Política e Democracia em tempos de Globalização, p.18.

7 In Revista da ESMAPE. Recife, vol. 3, n 7, Jan./Jun. 1998, pp. 156-157 apud Ivo Lantas, Direito Constitucional Econômico: Globalização \& Constitucionalismo, p. 113.

8 Direito e Globalização Econômica: implicações e perspectivas, p. 10-11. 
subseqüente revogação dos protecionismos tarifários, das reservas de mercado e dos mecanismos de incentivos e subsídios fiscais;

4 - desterritorialização e reorganização do espaço da produção, mediante a substituição das plantas industriais rígidas surgidas no começo do século $\mathrm{XX}$, de caráter "fordista", pelas plantas industriais "flexíveis", de natureza "toyotista", substituição essa acompanhada pela desregulamentação da legislação trabalhista e pela subsequiente "flexibilização" das relações contratuais;

5 - fragmentação das atividades produtivas nos diferentes territórios e continentes, o que permite aos conglomerados multinacionais praticar o comércio interempresa, acatando seletivamente as distintas legislações nacionais e concentrando seus investimentos nos países onde elas lhes são mais favoráveis;

6 - expansão de um direito paralelo ao dos Estados, de natureza mercatória ("lex mercatoria") como decorrência da proliferação dos foros de negociação descentralizados estabelecidos pelos grandes grupos empresariais".

Esses são os principais efeitos do processo globalizador. Vejamos, agora, como esse processo interfere na estrutura estatal, impondo-lhe, de certa forma, mudanças, de modo a se adequar à nova realidade mundial.

\section{Influência da globalização na reforma administrativa}

A globalização exige, como já ressaltado, a estabilização das macroeconomias e a redução da presença do Estado no campo econômico. Tais demandas requerem, inevitavelmente, a adoção de ajustes estruturais e privatizações.

É certo que as reformas empreendidas no Estado Brasileiro - com destaque para a reforma administrativa de 1998 - não têm por motivação apenas a globalização, tendo decorrido também de problemas intra-estatais.

Com efeito, passaremos a analisar os motivos que precederam e permearam a reforma administrativa brasileira - enfatizando a globalização como o principal deles - para depois avaliarmos, ainda que sumariamente, o conteúdo da reforma em apreço e o precioso papel do princípio da eficiência em seu contexto.

\subsection{Motivação da reforma}

Sabe-se que a reforma administrativa recentemente realizada no Brasil com a Emenda Constitucional no 19/98, não é um fenômeno exclusivo do país, mas sim uma experiência que vem sendo compartilhada por inúmeros países em resposta ao que se espera do Estado na atualidade.

"Mudam os paradigmas e modelos de gestão pública impulsionados a partir do segundo pós-guerra; as alternativas de substituição são objeto de um debate ainda aberto. É importante, contudo, sublinhar a universalidade desse processo. Com impulsos de políticas do mais diverso cunho ideológico, as estruturas estatais atravessam uma etapa de questionamentos profundos. Desregulamentação e privatização passam a ser aspectos centrais de uma mudança global que envolve governos, 
ideologias e estilos de gestão administrativa com relativa autonomia em função das condições concretas de cada país." 9

Realmente, "neoliberalismo" e "globalização" são conceitos que resumem bem os motivos que, do ponto de vista extra-estatal, contribuiram para a reforma administrativa do país. Por influência das idéias neoliberais, retomou-se o entendimento de que o Estado intervinha demais, sufocando, na verdade, a espontaneidade da iniciativa privada.

No tocante à globalização, temos que o intercâmbio multifacetário que esta promove entre os países demanda flexibilização, desregulação, privatização. Exige, enfim, desestatização, e, para tanto, a reestruturação de antigos arquétipos estatais.

Ficou claro para o mundo que, com o encerramento dos grandes debates ideológicos entre as nações, não havia mais motivo para elas se apegarem tão drasticamente ao nacionalismo. Com efeito, tornou-se uma tendência a união dos Estados em blocos econômicos que lhes dariam mais força comercial e competitividade mundial.

Internamente, a suscitar uma reforma na Administração Pública, tínhamos o problema de uma Constituição Federal obsoleta em muitos aspectos, além de um exacerbado endividamento público proveniente, principalmente, do alto custo com o pagamento dos servidores públicos.

Segundo alguns juristas, a questão constitucional era e ainda é séria. Para eles, a Constituição de 1988 não foi aparelhada para enfrentar os problemas do fim do século, tais como a concorrência de mercado e a globalização; tanto que já conta com vinte e duas emendas.

O Estado do Bem-Estar, cultivado pela Constituição de 1988, tinha como característica estar presente nos mais variados campos sociais: previdência, ensino, pesquisa, assistência social, tendo iniciado com a Carta Constitucional de 1934 e chegado à exaustão na Carta Constitucional de 1988, principalmente por "não ter conseguido expandir essa idéia de bem-estar para a maioria da população brasileira". ${ }^{10}$

Com efeito, inseriu-se no texto constitucional mais direitos do que se pôde ou se poderia alcançar, verificando-se que tais previsões implicaram mais em frustrações que propriamente em conquistas.

Ademais, do ponto de vista intra-estatal, tivemos também a alavancar a Reforma a crise das Fazendas Públicas, uma vez que estas estavam a empregar seus ativos, quase que integralmente, na remuneração de seus servidores, no pagamento de sua folha, situação esta agravada justamente com a instalação do regime jurídico único previsto na Constituição de $1988 .^{11}$

Finalmente, Sylvia Di Pietro ressalta, como outro motivo para a reforma, a procura desesperada por soluções; " a busca de institutos novos, de medidas inova-

9 Zuleta Puceiro, O Processo de Globalização e a Reforma do Estado, p. 105.

10 Francisco de Queiroz Bezerra Cavalcanti, O Novo Regime Previdenciário dos Servidores Públicos, p.14.

11 Ibidem, p. 94. 
doras, que permitam ao Estado lograr maior eficiência na prestação dos serviços que lhe estão afetos" 12 .

\subsection{Contornos da reforma}

"A expressão reforma do Estado designa a tendência, hoje praticamente universal, de reformar o aparelhamento do Estado, em especial, o aparelhamento administrativo, representado pela Administração Pública em sentido amplo, abrangendo todos os órgãos, dos três Poderes, que exercem a função administrativa" ${ }^{13}$.

"O modelo a transformar é antes de tudo, o de um Estado ineficiente como produtor, regressivo e desigual como distribuidor, árbitro interessado e tendencioso de disputas intersetoriais e interrrupções constantes da legalidade constitucional. Um tipo de 'absolutismo ineficaz', revelador da debilidade de uma sociedade corporativizada, incapaz de cumprir sua função de mediação social e administração da complexidade." 14

Foi, possivelmente, na Inglaterra, com pioneirismo, que as experiências sobre o tipo de administração pública mais adequado às novas demandas da sociedades foram testadas, especialmente devido ao trabalho de Dereck Rayner, encarregado de promover a reforma administrativa no país.

Nos Estados Unidos, inobstante os esforços de Regan e Bush, os resultados foram mais modestos, muito embora tenha sido criada a noção de produtividade, até então estranha à gestão pública.

Já no Japão e na Suécia, o processo de reforma administrativa centrou-se no consenso dos atores envolvidos, tornando-se, por isso, uma experiência exitosa, comparada a outras.

"Mas, possivelmente, os analistas políticos e os cientistas da administração pública, que amanhã se debruçarem sobre os modelos de reforma executados neste século, destacarão o da Nova Zelândia, promovida entre 1984 e 1994, como uma das mais bem conduzidas do planeta. Nem por outro motivo, esse País logrou ostentar, a partir de então, uma das maiores taxas de geração de empregos e de prosperidade geral em todo o mundo.

O exemplo é particularmente valioso porque a Nova Zelândia partiu de uma situação muito semelhante à brasileira, com o Estado presente em todos os setores da economia de alguma importância e responsável pela formulação da 'política de bem-estar' da Nação. Em dez anos, as transformações foram tão cuidadosamente executadas que acabaram se tornando um exemplo acadêmico." 15

12 Maria Sylvia Zanella Di Pietro, Parcerias na Administração Pública: concessão, permissão, franquia, terceirização e outras formas, p. 37.

13 Ibidem, p.39.

14 Zuleta Puceiro, O Processo de Globalização e a Reforma do Estado, p. 116.

15 Diogo de Figueiredo Moreira Neto, Coordenação Gerencial na Administração Pública, p. 40-41. 
Finalmente, apenas para citar a experiência latino-americana na modernização da administração pública, merecem destaque os exemplos do Chile e da Argentina como países que se adiantaram no processo de reforma administrativa.

No Brasil, os objetivos da reforma foram traçados no Plano Diretor da Reforma do Aparelho do Estado, elaborado pelo Ministério da Administração Federal e da Reforma do Estado - MARE - e aprovado em 1995.

Das idéias que se extraem no Plano Diretor destaca-se a de transformar a administração pública burocrática, altamente ineficiente, numa administração pública gerencial, voltada para atender com eficiência o cidadão e restringir custos desnecessários.

Houve também, com a reforma, mudança nos setores em que era dividido o Estado. Tradicionalmente compartimentalizado para atender a três tipos de atividades - serviços administrativos, serviços comerciais e industriais e serviços sociais o Estado passou a ter quatro setores de atuação: núcleo estratégico, atividades exclusivas, serviços não exclusivos e setor de produção de bens e serviços para 0 mercado.

O núcleo estratégico foi criado para modernizar a administração burocrática, mediante uma política de profissionalização do serviço público, acompanhada de avaliação de desempenho dos servidores e supervisão dos contratos de gestão firmados com agências autônomas ou organizações sociais.

Já o setor de atividades exclusivas tem por objetivo obter maior participação popular na fixação de políticas públicas, viabilizando o controle social das mesmas. Paralelamente, o setor de serviços não exclusivos prevê o programa de publicização, mediante o qual as atuais fundações públicas serão transformadas em organizações sociais, noutras palavras, em entidades públicas não estatais. Por último, o setor de produção para o mercado se propõe a dar continuidade ao programa de privatização.

$\mathrm{Na}$ fixação desses objetivos globais, nota-se a perene preocupação com a eficiência e com a participação da sociedade na gestão da coisa pública.

\section{O princípio da eficiência no contexto da reforma}

Conforme já frisado, a Emenda Constitucional no $19 / 98$ acrescentou expressamente aos princípios constitucionais da Administração Pública o princípio da eficiência. Com essa inclusão, findaram-se as inúmeras discussões doutrinárias e jurisprudenciais acerca de sua existência implícita no seio da Constituição Federal.

Na doutrina já se apontava a existência do princípio da eficiência em relação à Administração Pública, sob o argumento de que o art. 74, II, da Constituição Federal estabelece a necessidade de controle interno na três esferas de Poderes, com a finalidade de comprovar a legalidade e avaliar os resultados quanto à eficiência da gestão orçamentária, financeira e patrimonial nos órgãos e entidades da Administração federal, bem como da aplicação de recursos públicos por entidades de direito privado.

No tocante à jurisprudência, o Superior Tribunal de Justiça já tinha reconhecido a existência do princípio da eficiência como um dos regentes da Administração, ao 
externar o seguinte posicionamento: “a Administração Pública é regida por vários princípios: legalidade, impessoalidade, moralidade e publicidade (Const., art. 37). Outros também se evidenciam na Carta Política. Dentre eles, o princípio da eficiência. A atividade administrativa deve orientar-se para alcançar resultados de interesse público." 16

Em decorrência da indiscutível relevância desse " novo" princípio, como diretriz do modelo de Administração Pública que se quer cada vez mais imprimir ao Estado brasileiro, dedicamos-lhe todo um capítulo, de modo a tratar do tema de forma mais apurada.

\subsection{Significado de eficiência}

O administrador público deve ser eficiente, isto é, deve ser aquele que obtém bom resultado, velando pela objetividade e imparcialidade. "Assim, princípio da eficiência é o que impõe à administração pública direta e indireta, e a seus agentes a persecução do bem comum, por meio do exercício de suas competências de forma imparcial, neutra, transparente, participativa, eficaz, sem burocracia e sempre em busca da qualidade, primando pela adoção dos critérios legais e morais necessários para a melhor utilização possível dos recursos públicos, de maneira a evitarem-se desperdícios e garantir-se maior rentabilidade social. Note-se que não se trata da consagração da tecnocracia, mas, muito pelo contrário, o princípio da eficiência dirige-se para a razão e fim maior do Estado, a prestação dos serviços sociais essenciais à população, visando à adoção de todos os meios legais e morais possíveis para satisfação do bem comum." 17

Para Maria Sylvia Zanella Di Pietro, o princípio da eficiência "impõe ao agente público um modo de atuar que produza resultados favoráveis à consecução dos fins que cabem ao Estado alcançar". No entanto, adverte ela que "a eficiência é princípio que se soma aos demais princípios impostos à Administração, não podendo sobrepor-se a nenhum deles, especialmente ao da legalidade, sob pena de sérios riscos à segurança jurídica e ao próprio Estado de Direito." 18

Aqui é interessante observar que alguns doutrinadores não aceitam o princípio da eficiência como tal, ou seja, como princípio. Maurício Ribeiro Lopes, criticando a adoção do princípio da eficiência coloca que "eficiência, ao contrário do que são capazes de supor os próceres do Poder Executivo federal, jamais será princípio da Administração Pública, mas sempre terá sido — salvo se deixou de ser em recente gestão política - finalidade da mesma Administração Pública." 19

Convém ressaltar, finalmente, que o princípio da eficiência, além de extremamente vinculado ao princípio da legalidade, como destacado, está intrinsecamente relacionado também aos princípios da razoabilidade e da moralidade. Ao da razoa-

16 STJ - 6" T. - RMS n² 5.590/95-DF, Diário da Justiça, Seção I, 10 jun. 1996. p. 20.395.

17 Alexandre de Moraes, Reforma Administrativa, p. 28

18 Direito Administrativo, p. 73-74.

19 Maurício Antônio Ribeiro Lopes, Comentários à reforma administrativa, p. 108. 
bilidade porque o administrador deverá adotar critérios razoáveis por ocasião de sua atividade discricionária, evitando, dessa forma, cometer abusos; ao da moralidade porque a imoralidade administrativa é, em si, um ato que representa ineficiência grosseira.

\subsection{Conteúdo axiológico do princípio}

Visto o conceito do princípio da eficiência, podemos afirmar que ele possui como características: o direcionamento dos serviços públicos à efetividade do bem comum, imparcialidade, neutralidade, transparência, participação e aproximação dos serviços públicos da população, eficácia, desburocratização e busca da qualidade.

No tocante à primeira característica elencada - serviços direcionados à efetividade do bem comum - pode-se dizer que a promoção do bem comum encontra-se prevista no inciso IV, do art. $3^{\circ}$, da Carta Magna, como um dos objetivos fundamentais da República Federativa do Brasil. Às autoridades dos três Poderes, ao Ministério Público e ao intérprete em geral, esse objetivo deverá servir como diretriz de interpretação.

Quanto à característica de imparcialidade, temos que uma atuação eficiente da Administração Pública exige atuação imparcial, e imparcialidade significa "independência perante os interesses privados, individuais ou de grupo; independência perante os interesses partidários; independência, por último, perante os concretos interesses políticos do governo." 20

No que tange à neutralidade, pode-se dizer que ser neutro significa ser justo. A Administração Pública é neutra quando estabelece regras do jogo justas e quando assume uma posição que valorize todos os interesses em jogo da mesma forma. A neutralidade não significa abstenção, mas sim atitude de isenção na valoração de interesses em conflito.

Ademais, dentro da idéia de eficiência encontra-se a necessidade de transparência dos órgãos e agentes públicos, o que significa, em linhas práticas, o combate a subornos, corrupção e tráfico de influência, bem como a exclusiva observância de fatores objetivos, como mérito funcional e competência, por ocasião da indicação, nomeação e manutenção de cargos e funções públicas, afastando qualquer favorecimento ou discriminação.

A participação e aproximação dos serviços públicos da população deverá existir para concretizar a gestão participativa dos serviços administrativos. A gestão participativa significa verdadeiro desmembramento do princípio da soberania popular e democracia representativa, traduzindo-se na intervenção, sobre órgãos de gestão dos serviços públicos, não apenas de profissionais burocratas, mas também de representantes das comunidades em que os serviços estão inseridos. Eis aí outra faceta do princípio da eficiência.

20 Maria Teresa de Melo Ribeiro, $O$ princípio da imparcialidade da administração pública, p. 170. 
Outra característica do princípio da eficiência, conforme nos é apresentado por Alexandre de Morais $^{21}$, é a eficácia. Basicamente, a eficácia dos serviços prestados pela Administração Pública está atrelada ao grau de liberdade posto a disposição da Administração para dar cumprimento às suas complexas tarefas. A grosso modo, podemos dizer que a eficácia traduz-se na execução e no cumprimento pelos entes administrativos dos objetivos que lhe são próprios.

A desburocratização como característica do princípio da eficiência é elementar. Significa, em linhas gerais, que se deve evitar exigências desnecessárias, rotina e demora na resolução de assuntos dos cidadãos.

Por último, no tocante à busca da qualidade, quer-se dizer que se deve sempre visar a otimização dos resultados através da aplicação certa da quantidade de recursos e esforços, tendo por fim maior a satisfação do administrado. A noção moderna de qualidade total na Administração Pública foi seguramente importada do setor privado, traduzindo-se na busca de uma melhoria permanente, incansável, dos serviços públicos.

Um sistema de qualidade bem estruturado é um valioso recurso gerencial na otimização e no controle da qualidade em relação às considerações de risco, custo e benefício.

\section{Conclusão}

\subsection{Inserção constitucional}

Sempre se falou que os princípios jurídicos tinham mais força que os textos legais, vez que eram e são as vigas mestras de todo sistema e da própria ciência do Direito. No entanto, a praxis jurídica apontava em direção contrária, mostrando que, na realidade, o apego à lei formal era muito maior.

Nas últimas décadas, entretanto, esse quadro tem sido alterado, em especial com a positivação dos princípios nas Constituições. Hoje não há quem não conheça e não debata acerca dos princípios do direito adquirido, da isonomia, da irretroatividade da lei, da legalidade, e agora também da eficiência.

Os princípios fundamentais estão lá na Carta Magna. Os princípios de Direito Administrativo, encontram-se elencados no capítulo constitucional referente à Administração Pública. Os princípios tributários, são facilmente visualizados na parte da Constituição referente ao Sistema Tributário Nacional. A Constituição, enfim, por ser a Lei Maior do país, vista e revista por todos, todos os dias, tem efetivamente ajudado a "popularizar" os princípios jurídicos no mundo do Direito. Até os mais leigos sabem hoje que têm direito, por exemplo, à igualdade e à liberdade.

Paralelamente tivemos grandes juristas que há apenas meio século atrás debateram, problematizaram a discussão acerca dos princípios jurídicos de forma exem- 
plar, brindando-nos com uma concepção de princípios mais moderna, que os vê como norma jurídica e não apenas como diretrizes do ordenamento.

Esse reconhecimento, praticamente acolhido por todos aqueles que pensam o Direito, tem inegavelmente conferido aos princípios maior força empírica, o que é extremamente positivo.

No embalo dessas idéias, a eficiência - também inserida dentre os princípios constitucionais por meio da Reforma Administrativa de 1998 - passa, agora, a poder imprimir a força que a posição "constitucional" lhe confere.

\subsection{Fortificação da eficiência}

O impacto da globalização sobre o princípio da eficiência pode ser sentido na medida em que o transformou em "princípio-norma" de caráter constitucional e, como tal, passível de maior força e poder de coação.

Antes da reforma administrativa promovida sob os ventos da globalização, o princípio da eficiência, muito embora existente na Administração Pública, do ponto de vista lógico, era, sob o aspecto prático, inexpressivo.

No capítulo destinado à eficiência, vimos o quanto o mesmo era insípido no nosso ordenamento jurídico e como, em contrapartida, afloraram os debates sobre sua natureza e importância após ser inserido na Constituição Federal.

Na verdade, a Administração Pública sempre foi considerada ineficiente, especialmente por parte dos administrados, já conformados com o sistema viciado, absurdamente burocrático e emperrado dos serviços públicos.

A inclusão da eficiência dentre os princípios constitucionais da Administração Pública deu à máquina administrativa nova roupagem, proporcionando-lhe a revisão de suas prioridades, agora atreladas à idéia de dinamismo e celeridade.

Hoje, podemos seguramente afirmar que a concepção de eficiência cresceu e difundiu-se ao ser transformada em princípio constitucional.

Ainda é cedo para colher os frutos dessa alteração. O certo é que a globalização foi uma de suas "molas propulsoras", proporcionando a inserção explícita do princípio da eficiência no seio constitucional.

\section{Bibliografia}

BASTOS, Celso Ribeiro. Curso de direito administrativo. São Paulo: Saraiva, 1999. BULOS, Uadi Lammêgo. Reforma administrativa — primeiras impressões. Revista de Direito Administrativo $\mathrm{n}^{\circ}$ 214. Rio de Janeiro: Renovar, out./dez. 1998, pp.69-98.

CAVALCANTI, Francisco de Queiroz Bezerra. O novo regime previdenciário dos servidores públicos. Recife: Nossa Livraria, 1999.

DALLARI, Adilson Abreu. Administração pública no estado de direito. Revista trimestral de Direito Público n 5, 1994, p. 39.

DANTAS, Ivo. Direito Constitucional Econômico: constitucionalismo \& globalização. Curitiba: Juruá, 1999. 
DE MORAES, Alexandre. Reforma administrativa - Emenda Constitucional $n^{o}$ 19/98. São Paulo: Atlas, 1999.

DI PIETRO, Maria Sylvia Zanella. Parcerias na administração pública: concessão, permissão, franquia, terceirização e outras formas. São Paulo: Atlas, 1999.

Direito administrativo. São Paulo: Atlas, 1998.

FARIA, José Eduardo (org). Direito e globalização econômica: implicações e perspectivas. São Paulo: Malheiros Editora Ltda., 1998.

GÓMEZ, José Maria. Política e democracia em tempos de globalização. Petrópolis: Editora Vozes, 2000.

HARGER, Marcelo. Reflexões iniciais sobre o princípio da eficiência. Repertório IOB de Jurisprudência, $\mathrm{n}^{\mathrm{Q}}$ 16/99, caderno 1, p. 494-498.

LOPES, Maurício Antônio Ribeiro. Comentários à reforma administrativa. São Paulo: Editora Revista dos Tribunais, 1998.

LOUREIRO, João Carlos Simões Gonçalves. O procedimento administrativo entre a eficiência e a garantia aos particulares (algumas consideraçôes) Boletim da Faculdade de Direito - Universidade de Coimbra. Coimbra Editora, 1995.

MEDAUAR, Odete. Direito administrativo moderno. São Paulo: Editora Revista dos Tribunais, 1999.

MOREIRA NETO, Diogo de Figueiredo. Apontamentos sobre a reforma administrativa. Rio de Janeiro: Renovar, 1999.

. Coordenação gerencial na administração pública. Revista de Direito Administrativo no 214. Rio de Janeiro: Renovar, out/dez. 1998, pp. 35-53.

Globalização, regionalismo, reforma do estado e da constituição. Revista de Direito Administrativo $\mathrm{n}^{\circ}$ 211. Rio de Janeiro: Renovar, jan/mar. 1998, pp. 1-20.

Mutações no direito administrativo. Rio de Janeiro: Renovar, 2000.

PEREIRA, Cláudia Fernanda de Oliveira. Reforma administrativa - o estado, o serviço público e o servidor. Brasília:Brasília Jurídica, 1998.

PUCEIRO, Zuleta. O processo de globalização e a reforma do estado. Direito e Globalização Econômica: Implicações e Perspectivas. São Paulo: Malheiros Editores, 1998.

RIBEIRO, Maria tereza de Melo. O princípio da imparcialidade da administração pública. Coimbra: Almedina, 1996.

SARMENTO, Daniel. Constituição e globalização: a crise dos paradigmas do direito constitucional. Revista de Direito Administrativo n⿳0 215. Rio de Janeiro: Renovar, jan/mar. 1999, pp. 19-34.

SOUTO, Marcos Juruena Villela. Desestatização, privatização, concessões e terceirizações. Rio de Janeiro: Editora Lumen Juris, 2000. 